\title{
Shared accommodation as a globalization trend in tourism
}

\author{
Miroslava Kostková ${ }^{1, *}$ \\ ${ }^{1}$ Silesian University in Opava School of Businesss Administration in Karvina, Univerzitní nám. \\ 1934/3 73340 Karviná, Czech Republic
}

\begin{abstract}
Modern tourism trends have a distinctly global character. They include the use of online tourism service platforms and the sharing of services based on sharing economy. Governments and municipalities create regulatory measures to operate in accordance with the destination's municipal, financial, security, and tourism interests to ensure transparency and a level playing field for entrepreneurship. The paper deals with this global trend in the field of the accommodation services through the Airbnb platform in the Czech Republic and in the Silesian Moravian Region, in the use and provision of tourist accommodation services and identification of the impact on tourism development and tourist attendance the destination, within the project Trends of tourism in the Moravian-Silesian Region, using the methods of marketing research. The results declare that shared economy platforms in the field of accommodation have a place in the modern economic system, they put competitive pressure on tourism service providers, the offer expands for the consumers and traditional service providers force to move to innovative concepts. The hoteliers want to offer the creation of standards that the sharing accommodation providers should follow and public administration and city representatives want to clearly describe the duties for each accommodation provider and regulate accommodation through Airbnb.
\end{abstract}

\section{Introduction}

The hospitality sector is one of the key drivers of the globalized European economy, in terms of both employment and direct contribution to the economy. It is the third strongest socio-economic activity in the EU. It is an increasingly efficient market platform, accounting for 2.9\% of the Czech Republic's GDP and generating 231,000 jobs. Accommodation and catering services account for more than half of total income from tourism. Accommodation expenditure is one of the largest items in tourist budgets and is an important inflexion point for exploring evolving trends in types of tourist accommodation. Airbnb and traditional hotels compete for travellers across a wide range of market segments, but the substitutability of their offers are constrained in specific city areas [5].

\footnotetext{
*Corresponding author: kostkova@opf.slu.cz
} 


\section{Theoretical background}

New digital technologies not only support consumers in better fulfilling their own consumption needs but also enable to create them greater value for other consumers, who are also co-producers [10]. A business model based on asset sharing, exchange or lease is referred to as the "Sharing economy".

New sharing economy mechanisms are demonstrating just how such technologies can make transactions more accessible to owners and users of the property, the authors $[7,1$, $17,2]$ solute how to use cooperation platforms, from the sharing economy and technology platforms to assist with matching owners of under-utilized resources with individuals interested in accessing or using those resources. The motivation of the users, aiming to shed light on their values, lifestyles and consumption preferences was explored by [18]. Other authors explore how culture affects the nature and level of rent-seeking that society pursues and whether institutional shifts can strengthen or break down that explores [13]. The customers purchase different services based on their preferences and optimal perceived of the value in the sharing economy - determining the drivers of user loyalty. Their loyalty from a customer perspective and the impact of different value perceptions for customer-tocustomer-based platforms [18,9]. The characteristics of Airbnb networks in the context of the potential impact on local residents and the traditional hotel industry was examined by [11] and [12], examined was a motivation of sharing economy users and why people participate in collaborative consumption. Platform-based business models have become such an essential pillar of today's economy [6]. The success of platforms such as Airbnb is evidence of a shift from an ownership society to a sharing society. However, only very few platforms are able to accumulate a large and loyal following of customers [9, 19]. In the research approached this challenge by researching platform loyalty motivators of the guests and soluted, that accommodation sharing provides unique experiences for tourists. They extracted the following dimensions contributing to the core experiences of sharing: housing, location, host-guest interaction, facility, overall sensation and others. It demonstrated a strong association between attributes of sharing experiences and guest satisfaction. According to [8] high ratings seem to be the a norm in most online platforms that include consumer reviews, but the case of Airbnb seems more extreme than the others.

Spaces advertised by Airbnb vary widely, ranging from a living room to entire islands, but typically involve a private room, apartment, or entire house. Since its inception in 2017 Airbnb has grown to more than 3 million listings, serving 65,000 cities in 191 countries, and has booked in excess of 200 million guests. Airbnb has approximately 24 competitors in the same market space. These include: 9flats, Alterkeys, Atraveo TUI Group, Benivo (formerly FlatClub), Couchsurfing, Flat4Day, Flipkey, HomeAway, Home Escape, HouseTrip, iStopOver, Kozaza, Localo, Nestpick, Onefinestay, Roomorama, SunnyRentals, TravelRent, Trip.com, Upiq, VRBO, Wimdu, Wyndham Worldwide, and Zukbox. Airbnb's success points to high demand for such accommodation due to attractive prices, connecting with locals, and exploring off the beaten track experiences. It is possible, however, that we are not experiencing an overall change in preferences with respect to platforms such as Airbnb, but an adaptation or evolution on a generational level [11]. The primary competitive advantage of $\mathrm{P} 2 \mathrm{P}$ platforms lies in their ability to avoid costly regulations that are meant to protect third-parties. Consumer welfare is enhanced by offering new innovations, more choice, greater service differentiation, better prices and higher quality services. Further, the sharing economy removes the need for regulation in several instances, by providing better information and reputation systems, and expanding choices available to consumers. Unlike the traditional hotel industry, consumers using Airbnb must market themselves in ways that will maximize their chance of securing permission to book. Hosts' risk assessment of a potential booking depends in part on trip-related characteristics (for example, the number of nights, motivation for the trip, the travel party, and guests' self- 
description of their behavior) as well as personal characteristics (for example, gender, age, and features of the profile picture) [9]. The most important attribute is self-description by guests of their positive behaviour, a profile picture, and trip purpose. Airbnb enables private citizens to become micro-entrepreneurs, offering their accommodation to tourists for a fee. Hosts have the potential to earn substantial income by renting out their accommodation. The importance of attributes such as the location, reputation, comfort, personality and behaviour and the expectations of higher rental prices associated with pricing are demonstrated [9].

\section{Methods}

A sharing economy consists of renting, exchanging or sharing property among people. According to a survey by Ipsos for the Czech Association of Shared Economy in 2018 [15] a quarter of a thousand Czech respondents try out the services of a shared economy. Most often they rent housing (29\%), $8 \%$ of people now offer their services or property in this form, another $10 \%$ are planning to do so. People with shared economy services most often rent accommodation (35\%). Those who are just about to do so also consider renting the most $(33 \%)$.

The largest provider of this service is Airbnb, founded in San Francisco in August 2008 by Brian Chesky and Joe Gebbia with the bold idea: "Invite the world to your home. For the money." They created a global portal where people can offer or search for places to stay around the world. For tourists, the service offers a cheaper alternative to hotel accommodation and landlords financial income. The ideal members of the Airbnb community are the so-called digital nomads who can save up to $80 \%$ on their costs. Airbnb has 800 million accommodations worldwide in some 34,000 cities in 190 countries, with an estimated value of $\$ 31$ billion. Airbnb earns money from fees charged to guests $(6-12 \%$ depending on the price of the reservation). Lessor withdraws $3 \%$ of the price of each booking as a transaction fee, with no initial investment per issue. The competition service HomeAway, HouseTrip, 9flats, Interhome, Booking, Idealista charge the registration fee.

Airbnb has been operating in the Czech Republic since 2009. According to expert analyses [4] Airbnb's services in Prague have already equalled the volume of trade in conventional accommodation facilities. The number of guests staying in the Czech Republic through the Airbnb application increased by 52\% last year. In 2018, more than a million people used the service of the Airbnb for accommodation in the Czech Republic, and more than 420,000 people travelled from the Czech Republic abroad with the help of Airbnb. According to Airbnb, the Czech Republic is home to a lively community of hosts who have welcomed tourists from more than 150 countries. In 2018 Airbnb's share in the number of overnight stays in Prague yearly increased to $14.7 \%$. This is higher than in London (6.9\%), Amsterdam (11.8\%), Berlin (6.5\%) or Madrid (10.1\%), but less than in Paris $(15.2 \%)$. The analysis of the Municipal Institute of Planning and Development of IPR (solving the ways of legislative grasping of services based on modern technologies) shows that there are 650,000 flats only in Prague and the number of flats offered via Airbnb is approximately 11,500 , ie $1.4 \%$ of the housing stock. In the narrowest historical centre of Prague every fifth apartment. Almost $84 \%$ of Airbnb's beds are available in Prague 1 and Prague 2 (the most popular locations are New Town, Old Town and Zizkov). In Prague, the Airbnb offer is higher than in Vienna, Warsaw or Budapest. Last year, guests booked 1.79 million overnight stays in Prague, spending an average of $€ 75$ per night, which is also higher than in Berlin, equivalent to the price of accommodation in Madrid, while the number of properties booked in Prague is significantly lower [3]. According to the type of 
accommodation shared rooms accounted for $1.1 \%$, room rental $17.9 \%$ and $81 \%$ rental of the whole household.

Prague is traditionally the strongest destination, but in the regions outside Prague, interest increased by $108 \%$ last year. Guests stayed at about 11,000 hosts. The highest number of visitors came from Germany and the USA, on average on 3.3 nights. Outside Prague, the greatest interest is in South Moravia and Silesia. In addition to Airbnb, on the Czech market offer the other similar services Flipkey, HomeAway, House Trip, Vacation Rentals and Vrbo. Czech brands such as Liftago, Flatio have a good reputation with consumers, and Flatio has doubled the number of flat rental providers. Airbnb with its services in Prague equalized the volume of trade of classic accommodation facilities [14]. However, the Czech Republic has a below-average share in the provision of shared economy services within Europe according to Eurostat data (Table1).

Table 1. Peer to peer accommodation in Europe

\begin{tabular}{|l|c|l|c|l|l|}
\hline Country & $\mathbf{\%}$ & Country & $\mathbf{\%}$ & Country & $\mathbf{\%}$ \\
\hline Great Britain & 34 & France & 16 & Latvia & 16 \\
\hline Luxemburg & 22 & Slovakia & 16 & Lithuania & 16 \\
\hline Ireland & 21 & Sweden & 16 & Finland & 16 \\
\hline Malta & 20 & Estonia & 15 & Bulgaria & 15 \\
\hline Netherland & 20 & Poland & 15 & Austria & 15 \\
\hline Belgium & 19 & Monte Negro & 15 & North Macedonia & 15 \\
\hline German & 19 & Ungaria & 13 & Croatia & 13 \\
\hline Spain & 18 & Serbia & 12 & Portugal & 12 \\
\hline Italy & 17 & Norway & 11 & Rumunia & 11 \\
\hline Iceland & 17 & Denmark & 10 & Cyprus & 10 \\
\hline EU median & $\mathbf{1 7}$ & & & Czech Republic & $\mathbf{1}$ \\
\hline
\end{tabular}

According to a survey conducted by Behavio in 2018 about Airbnb's perception of services, $79 \%$ of 576 respondents choose this service because they want to stay there locally, $89 \%$ say it is more comfortable than a hotel. It is unequivocally rejected by $3 \%$ of people. $22 \%$ are neutral and $10 \%$ of respondents expressed support. The main reasons for the negative attitude are rising rental prices, concerns about security risks, increased noise in houses where apartments are rented in this way. Two-thirds of the survey participants do not consider the effects of shared accommodation applications as a problem. As a positive, he mentions a cheaper alternative to hotels. $28 \%$ of the respondents are against any regulation, the unification of rules for Airbnb and hotels supports 52\%. Respondents support the transfer of the obligation of fees from the landlord to Airbnb, which at the same time must provide the city with information about the residents in a particular city. People prefer renting an entire apartment or house over a cheaper room. The average Airbnb host in the Czech Republic is 38 years old, men and women are equally represented. The shortterm rentals are the owners most interested in the summer season when the average apartment turns up to seven different guests. On the other hand, the lowest interest in shortterm rentals is in February.

This global trend also poses a number of problems. While collective accommodation establishments meet hygiene regulations, register guests, pay fees and pay taxes, some apartment owners avoid these obligations. Shared housing, according to realtors, increases property prices, encourages speculation with apartments, reduces the supply of classic residential housing and affects the rise in prices for classic rents. It also addresses the coexistence of residents and tourists, who often alternate in the neighbouring apartments of one house, disturbing community life (a problem with tourists who come only for drinking alcohol and entertainment). Renting flats via Airbnb is a burden on other users, annoys 
neighbours, increases noise at night, cleaning and lighting costs for common areas, and elevator operation. The authorities are not able to properly control the landlord and enforce the accommodation fee.

Large numbers of providers operating in a 'collaborative' economy are starting to resemble micro-enterprises [3]. Unbalanced and under-regulated markets distort competition in terms of supply and also withhold financial resources for the necessary innovations in the regulated sector. The unregulated "collaborative" economy also contributes to the congestion of some destinations (overtourism). Therefore, in 2018, the European Commission adopted measures to ensure the development of responsible and sustainable tourism to ensure a level playing field in an increasingly professionalized 'collaborative' economy. The aim is to ensure balanced and fair European markets, protect the interests of local people and citizens for better management of tourism flows. The European Commission's Agenda for the economy of sharing very liberally states on what basis it should be determined whether commercial activities are involved or not, the functioning of the shared economy is viewed positively. In European law, the Services Directive states that restricting market access is only permissible where it is necessary to safeguard the public interest. "Airbnbization" drives people out of the historic city centres and replaces them with tourists. Therefore, many cities tighten the rules for tourist rent by limiting the number of days a year:

London - Europe's No. 1 in Airbnb leases (6.7 million overnight stays), limited in 2016 to a maximum of 90 nights per year.

Berlin - the management of Berlin has decided to lift the Airbnb service ban that it introduced in 2016. However, apartment owners can rent their own home any way they want, but their other apartments only for 90 days a year. Authorization of the service is subject to fairly strict rules - property owners can only lease through Airbnb for a short period with the permission of their district (up to half a million euros).

Paris - the most rented city with 65 thousand apartments, a rent limited to 120 days per year, subject to registration. France is the second-largest Airbnb market after the USA.

Legislation that would limit the number of overnight stays to which real estate can be rented through any form of the sharing economy, unlike many European metropolises, does not yet exist in the Czech Republic. Nevertheless, the number of overnight stays via Airbnb increased significantly.

\section{Results and disscution}

From the perspective of foreign guests, the Czech Republic is still an attractive destination. The number of arrivals and overnight stays of foreigners in 2018 was the highest in the past. The attendance of collective accommodation establishments in the Czech Republic has been growing continuously for several years and the sharing economy does not endanger hotels in any way. These new services consume only some of the demand and hotels will retain a substantial part of it. On the contrary, according to the Czech Hotel and restaurant Association AHR $\breve{C}$, regulation in the accommodation sector should generally decrease, portals such as Airbnb should be obliged to disclose their data to authorities. Many short-term accommodations are covered by a rental agreement and there is no instrument to ensure that existing laws, including tax discipline, filing of foreigners with the Police, registration of the guests.

The Moravian Silesian region (MSR) currently registers 612 public accommodations. The number of overnight stays in public accommodation in MSR increased by $11 \%$ year on year in 2018 CzechTourism). The number of guests from abroad is also increasing. In 2018 , the guest stayed on average 3.6 nights, which is, however, above the national 
average. MSR currently offers more than 300 accommodation offers via Airbnb search result ad type: Ostrava, the Czech Republic from $\$ 10$ per night using our Airbnb, or: Rent Apartments in Ostrava, the Czech Republic from \$20/night. Although the MSK is in the 6th place in the Czech Republic's tourist attendance, its attractiveness, associated with technical monuments, music festivals, sports events, spas and the beautiful nature of the Beskydy Mountains, is growing.

The project "Trends of Tourism in the Moravian-Silesian Region", which was implemented in the period 2017-2019 on a sample of 400 respondents, examined changes in tourist trends and identified new trends in the field of tourism demand and supply of tourism enterprises. It looked at changes in consumer consumption behaviour, the way communication between travel service providers and customers, the importance of quality and certification, and the response to the introduction of new products in business offers. The survey confirmed that the consumer behaviour of tourists and visitors is subject to global trends, and new trends have also been identified (Fig. 1).

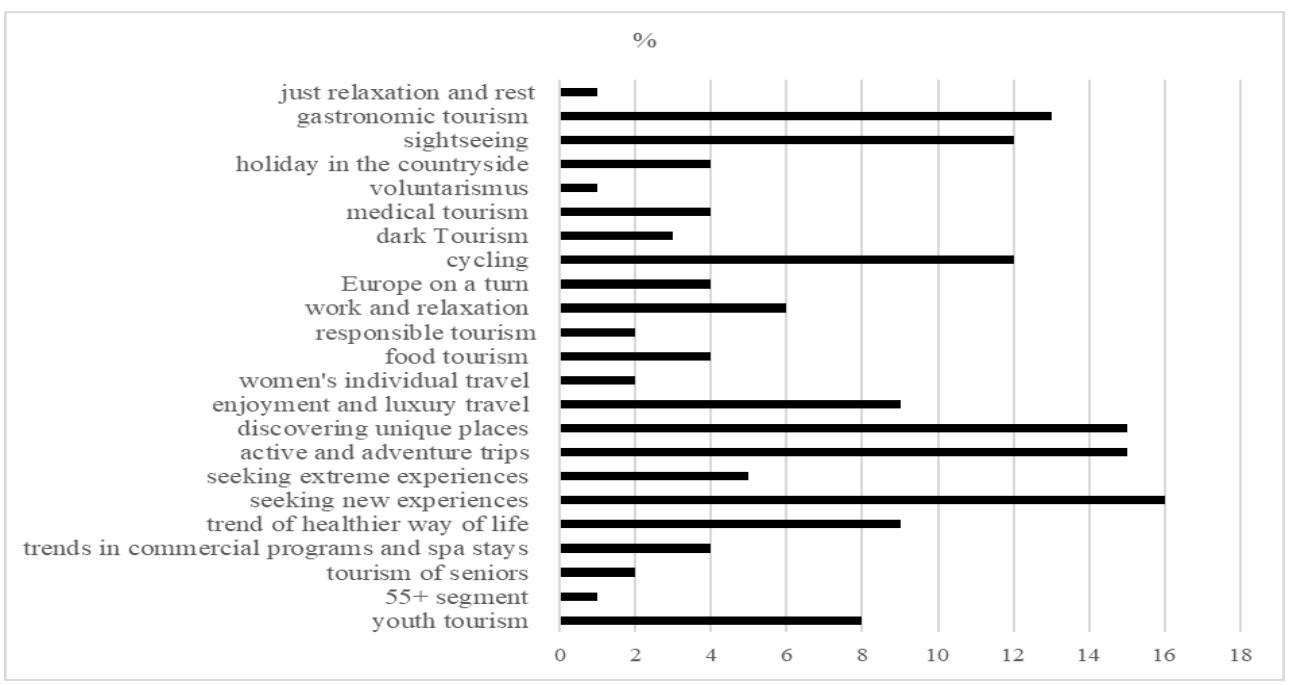

Fig. 1. Identified trends in tourism in MSR

The strongest tourist trends include searching for active forms of the holiday, searching for new experiences, buying services over the Internet and trying out new offers. These trends were also confirmed in a pilot survey of 45 respondents on consumer behaviour in use of Internet accommodation platforms in 2019. The survey shows that the trend of modern forms of leisure, travel, food, communication and exploitation of the shared economy is evident. $17 \%$ of respondents have already used one of the shared economy services on their journeys, $8 \%$ consider it better than collective accommodation, provide a higher level of freedom, save time and money, make comparisons of reviews and communicate over the Internet fast and easy. Factors that influence the interest in accommodation are the number of competitors and the location of the property, the description of the offer and guest rating, access and flexibility, photos and price.

The use of this platform in our country is currently not controlled. According to the Czech Financial Administration, $80 \%$ is not a sharing economy, but a business that is not taxed at the appropriate level (since 2018 it has been established that services offering accommodation over the Internet are accommodation services and not rent). Income from this activity is now subject to taxation and their providers should also pay the municipality accommodation fees (eg. Prague loses 160 million crowns on unpaid fees annually, the 
annual revenue of the hosts exceeds the threshold of two billion). According to the Analysis [11] more than $56 \%$ of all properties are offered by entities that have three or more properties on offer. Only $30 \%$ are individual offers and only $20 \%$ of the apartments offered are truly shared accommodation, where the host and the host dwell in the apartment - it is below average in Europe. Many entities dispose of dozens of accommodation capacities, it is no exception that one host owns more than 100 accommodation units for rent. Among these hosts, there are so-called market leaders according to the achieved turnover, which generates a turnover of several tens of millions of CZK per year.

Hoteliers and city representatives want to regulate accommodation in front of Airbnb. The public administration wants to clearly describe the duties for each accommodation provider, while the AHR ČR wants to offer the creation of standards that the accommodation providers should follow. European Hotel Confederation HOTREC plays a proactive role in the pursuit of a sustainable and responsible "collaborative" economy. It wants to revise the EU regulatory framework in order to identify platform responsibilities and ensure a fairer and more balanced digital single market in the light of new market conditions and to require online platforms to reflect market-based responsibilities.

Sharing economy is also a topic for the Czech government and relevant ministries. The government approved steps to regulate the sharing economy and adopted a resolution that enshrines this phenomenon in the Czech legal order. The Working Group on Shared Economy has prepared a legal and economic analysis. The Tax Administration has launched inspections of landlords through Airbnb, aimed at meeting the landlord's tax obligations (Airbnb keeps its users secret). Denmark is the first and so far the only country to sign a lease agreement directly with Airbnb. The company automatically sends information on property owners' income to the Danish tax authorities. Other states could introduce the same solution. Deputies do not agree whether digital accommodation platforms such as Airbnb or Booking should themselves pay the accommodation fees for their clients. At present, this is the responsibility of the accommodation owner himself, who often does not. The fee for exclusive sites could have a regulatory effect. Airbnb has recently announced that it is ready to start collecting accommodation fees for all its hosts and to transfer the proceeds to the municipality. An agreement to collect the relevant fee under a contract with the municipality could be the first in the Central and Eastern Europe.

Airbnb says it promotes local, authentic and sustainable tourism that will benefit as many people as possible. Therefore, the accommodation provider launches an initiative called the Office of Healthy Tourism, which emphasizes healthy tourism, for example by promoting lesser-known places or following environmental principles. Under the "Friendly Buildings by Airbnb" program, it plans to build about 20,000 homes for rent. The house will be closed for a year and can be rented for up to 180 days a year. The government is trying to reassure its neighbours' complaints about inappropriate behaviour by tourists in rented flats for cooperation and better visitor services, and the company is also trying to reassure some cities that are worried about the drop in accommodation.

\section{Conclusion}

In a world of technology-driven change, with more than 1 billion passengers annually, the rapidly evolving digital economy has made online platforms a gateway to the development of tourism, which is the engine of growth, sometimes in an uncontrolled way. In the new market conditions, traditional concepts need to be reconsidered. Promotion and regulation at European Union level considerably influence the opportunities for sustainability and further development of tourism at the national level. One of the priorities of the European Hospitality White Paper 2019-2024 is to address the so-called collaborative economy in order to ensure responsible and sustainable tourism and to improve the conditions for small 
and medium-sized businesses in the hospitality sector. Better balance and constant monitoring of developments in online platforms are needed to adapt to changing circumstances and protect the interests of all businesses and citizens.

Airbnb continues to grow rapidly in large cities, despite local authorities' efforts to curb it through new regulatory measures. Airbnb is penetrating new areas such as investing in the Danish company Guest, which specializes in reserving meeting places, small brainstorming meetings, but also larger meetings - the so-called Marketplace, where people offer and demand meeting space. The Airbnb for Work program is targeted at the business travel market, currently offering three thousand such places. A volume of GDP resulting from the sharing economy will continue to accelerate. This growth, however, requires effective regulation of the impacts of the sharing economy on the tax system, the pension system and at the same time on the rise in the price level due to the multiplication of intermediaries in supply chains. The aim of regulating shared accommodation is not to penalize but to anchor clear rules and ensure user-friendly procedures while minimizing the administrative burden.

The sharing economy has a place in the modern economic system. A shared economy brings new opportunities for technology and service interconnections, giving young people the opportunity to tap their potential and fill the market gap, creating new flexible jobs. Shared economy platforms put competitive pressure on providers in the traditional sector, consumers are expanding, and traditional service providers are forced to move on to innovative concepts to compare pace with new trends.

Online platforms play an increasingly important role in the economy. The impact, role and responsibilities of platforms have increased over the past years. Online platforms should commit to fair and transparent B2B and B2C relationships. Fairness in the platform economy is essential for investing sufficient resources in innovation.

The concept and the development of sharing economy are determined by economic, social and cultural factors. The concept of sharing economy can be discussed from the view of consumer protection law, employment law, personal data protection, competition law, state aid and other areas. There is a necessity to re-evaluate traditional concepts in the new market circumstances. Rules about new business models have multiple effects on all market participants. Sharing economy affects undertakings, market structure, the definition of the relevant market. There is a need for reconsideration of existing definitions and their flexible application to innovative business models.

\section{References}

1. J.H. Adler, Introduction: Property in ecology (Natural Resources Journal, 59, 1, 2019)

2. E. Aloni, Pluralizing the sharing economy ( Washington University Law Review, 91, 2019)

3. Analysis Colliers Int., 2018

4. Analysis of the Municipal Institute of Planning and Development IPR, 2018

5. P. Baresova, P. Stankova, Global Challenge: Population aging and their leisure time (Globalization and its Socio-Economic Consequences, 16th International Scientific Conference Proceedings, Pts I-V. Univ. Žilina, 2016)

6. J. Botlik, M. Botlikova, The development of tourism consumption in catering. (Globalization and Its Socio-Economic Consequences, 16th International Scientific Conference Proceedings, Pts I-V, Univ. Zilina, 2016)

7. R. Botsman, The sharing economy lacks a shared definition (Fast Company, Url: http://Www.Fastcoexist.Com/3022028/The-Sharing-Economy-Lacks-AShareddefinition, 2013) 
8. J. Bulchand-Gidumal, S. Melian-Gonzalez, Why are ratings so high in the sharing economy? Evidence based on guest perspectives (Tourism. Routledge Journals, 2019)

9. T. Clauss, P. Harengel, M. Hock, The perception of value of platform-based business models in the sharing economy: determining the drivers of user loyalty. (Review of Managerial Science, 13, 3, 2018)

10. B.G. Dellaert, The consumer production journey: marketing to consumers as coproducers in the sharing economy (Journal of the Academy of Marketing Science, 47, 2, 2019)

11. K. Gyodi, Airbnb in European cities: business as usual or true sharing economy? (Journal of Cleaner Production, 221, 2019)

12. J. Hamari, M. Sjoklint, A. Ukkonen, The sharing economy: Why people participate in collaborative consumption (Journal of the Association for Information Science and Technology, 67, 9, 2016)

13. S. Choi, V. Storr, A culture of rent seeking. (Public Choice, 181, 1-2, 2019)

14. Inside Airbnb 2018

15. Ipsos survey for the Czech Association of Shared Economy ČASE, 2019

16. E. Ketter, Eating with eatwith: Analysing tourism-sharing economy consumers (Current Issues in Tourism, 22, 9, 2019)

17. D.J. Kochan, The market to roam: Using sharing economy platforms for expanding roaming access to land resources (Natural Resources Journal, 59, 1, 2019)

18. Y. Zhou, X. Lin, Y. Zhong, W. Xie, Contract selection for a multi-service sharing platform with self-scheduling capacity (Omega-International Journal of Management Science, 86, 2019)

19. F.F. Xu, L.Q. La, F. Zhen, T. Lobsang, C. Huang, A data-driven approach to guest experiences and satisfaction in sharing (Journal of Travel \& Tourism Marketing, 36, 4, 2019) 